ENCYCLOPÉDIE Encyclopédie berbère

BERBERE

12 | 1993

12 | Capsa - Cheval

Caput Vada

(Qabboudiya, Ras Kaboudia)

P. Trousset

(2) OpenEdition

Journals

Édition électronique

URL : http://journals.openedition.org/encyclopedieberbere/2060

DOI : 10.4000 /encyclopedieberbere.2060

ISSN : 2262-7197

Éditeur

Peeters Publishers

Édition imprimée

Date de publication : 1 février 1993

Pagination : 1772-1774

ISBN : 2-85744-581-4

ISSN : 1015-7344

Référence électronique

P. Trousset, « Caput Vada », Encyclopédie berbère [En ligne], 12 | 1993, document C23, mis en ligne le

01 mars 2012, consulté le 25 septembre 2020. URL : http://journals.openedition.org/

encyclopedieberbere/2060 ; DOI : https://doi.org/10.4000/encyclopedieberbere.2060

Ce document a été généré automatiquement le 25 septembre 2020.

(c) Tous droits réservés 


\title{
Caput Vada
}

\author{
(Qabboudiya, Ras Kaboudia)
}

\section{P. Trousset}

1 Ce promontoire, appelé Ras Kaboudia sur les cartes actuelles, est la pointe la plus orientale de la côte de la Tunisie. Il est connu des auteurs anciens sous divers noms: c'est le Promontoire d'Ammon Balithon de Strabon (XVII, 3, 16), le Cap Brachodes de Ptolémée (IV, 3-4), le Caput vada - ou vadorum - de Procope (De Aedificiis, VI, 6) et de Corippe (Johan., I, 369), d'où dérive son nom actuel. Comme le soulignent ces dénominations, le cap en question marque à l'extrémité septentrionale de la Petite Syrte, le commencement des hauts-fonds (Brachodes = vada) qui s'étendent jusqu'aux bancs des îles Kerkennah. Ces hauts-fonds ont été de l'antiquité jusqu'à nos jours une zone favorable à la pêche: Strabon signale près de l'acra Ammonos Balithonos, la présence d'une guette à thon (tynoscopeion); des cuves de salaisons - interprétées alors comme les vestiges d'un therme - et les restes d'un centre habité par des pêcheurs ont été retrouvés près de la tour Khadija, lors de la construction d'une thonaire moderne aujourd'hui détruite par l'érosion littorale très active dans ce secteur. (Carton 1906, p. 133-134).

2 C'est à Caput Vada que l'expédition de Bélisaire prit terre en Afrique en 533. La presqu'île fut transformée en tête de pont protégée du côté de la terre par un fossé et une palissade. A cette occasion une source fut découverte, de bonne augure pour l'entreprise des Byzantins (Procope, De Bello Vandalico, III, 14-17). Plus tard, toujours selon Procope (De Aed, VI, 6), une ville florissante y fut fondée par Justinien pourvue d'un mur d'enceinte (teichos). Mais il n'est pas possible de prouver qu'elle s'appelait Justinianopolis comme l'affirmait Ch. Diehl (1896, p. 296) car ce nom semble avoir été réservé plutôt à Hadrumète (Pringle 1981, p. 192).

3 Le Ras Kaboudia est une presqu'île basse et étroite, rocheuse à son extrémité où se remarque une construction hétéroclite restaurée récemment, le Borj Khadija, destinée à contrôler un important mouillage à la limite nord des hauts-fonds (qsir). 


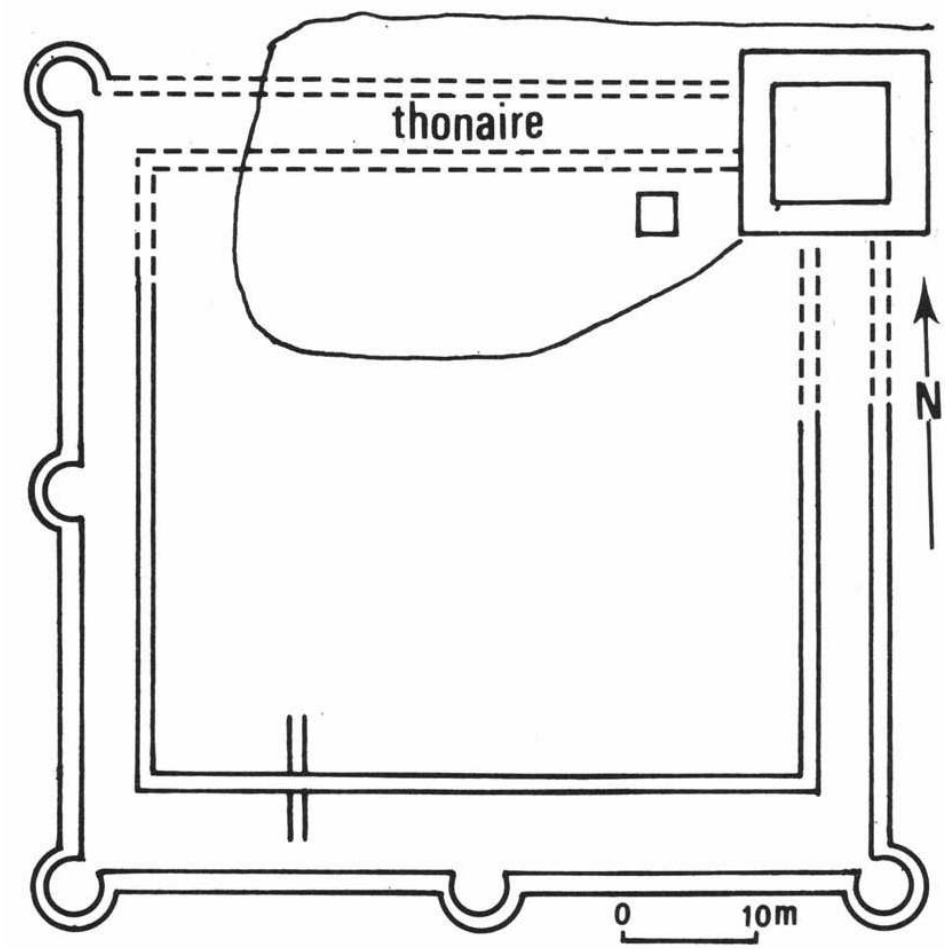

4 C'est une tour quadrangulaire de 9 mètres de côté à la base, flanquée à l'ouest d'une tourelle circulaire de 17,50 mètres de hauteur. Ce phare remanié à plusieurs reprises, est tout ce qu'il reste - à l'angle nord-est de celui-ci - d'un fortin de 67 mètres de côté flanqué de tours rondes et dont les autres vestiges ont disparu entre 1901 et 1906 (Carton 1906, p. 129). Il s'agissait d'un ksar-ribat construit par les Aghlabides au IX siècle et signalé par les auteurs arabes (Edrisi, trad. Dozy et De Goege, p. 149). Mais rien n'interdit de penser, à en juger par ses fondations en pierres de taille de grande dimension, qu'il ait pu succéder à une fortification plus ancienne d'époque byzantine.

Un trésor de monnaies byzantines datées du règne de Maurice Tibère (582-602) a été découvert récemment en bordure de mer, au Ras Kaboudia (Slim 1989, p. 529).

\section{BIBLIOGRAPHIE}

CARTON L., « Le Bordj-Khadidja (Chebba), Bull, de la Soc. archéol. de Sousse, 1906, p. 127-134.

DIEHL Ch., L'Afrique byzantine, histoire de la domination byzantine en Afrique (533-709), Paris, 1896, p. 269.

DJELLOUL N., Les installations militaires et la défense des côtes tunisiennes $d u X^{X} I^{e}$ au XIXe siècles, thèse Paris-Sorbonne, 1988, p. 542.

GUERIN V., Voyage archéologique dans la Régence de Tunis, Paris, 1962, 1, p. 149-150. 
HANNEZO G., « Chebba et Ras-Kaboudia », Bull, de la Soc. archéol. de Sousse, 1906, 8, p. 135-140.

PELISSIER E., Description de la Régence de Tunis, Paris, 1853 (rééd. Tunis, Bouslama, 1980), p. 99-100, 268.

PRINGLE D., The Defence of Byzantine Africa from Justinian to the Arab Conquest, Oxford, 1981, B.A.R., International Ser., 99, 1, p. 192.

SERVONNET J., LAFTTTE F., En Tunisie, Le golfe de Gabès en 1888, Paris, Challamel, 1888, p. 4-5.

SLIM H., « Trouvaille de monnaies byzantines en Tunisie », Bull. Soc. franc, de numismatique, 1989, 2, p. 529.

TROUSSET P., « Les défenses côtières byzantines de Byzacène », Roman Frontier Studies 1989,

Proceedings of the XVth International Congress of Roman Frontier Studies, University of Exeter Press, 1991, p. 349.

INDEX

Mots-clés : Antiquité, Tunisie 